\title{
Integral Transform Solution to the Endometrial Ablation Problem
}

amandapresgrave@ime.eb.br

\author{
R. O. C. Guedes \\ Emeritus Member, ABCM \\ guedes@ime.eb.br
}

\section{F. Scofano Neto}

Emeritus Member, $A B C M$ scofano@ime.eb.br

Instituto Militar de Engenharia - IME

Seção de Engenharia Mecânica e de Materiais 22290-270 Rio de Janeiro, RJ, Brazil
Menorrhagia is an ailment experienced by a significant number of women during their reproductive years. This condition is associated to heavy menstrual bleeding and while medical treatments are possible, its effects are quite limited. Surgical procedures often employ a hysterectomy but the total removal of the uterus involves high costs and also sometimes a moderate health hazard. Less invasive treatments were devised, and over the years a technique called endometrial ablation has become increasingly popular especially in the United States and in Europe. This treatment removes the endometrium by inserting a latex balloon filled with a solution at a high temperature inside the uterine cavity. Therefore, in order to assess the effectiveness of this treatment, accurate predictions of the temperature field are needed. The present contribution addresses this thermal problem and adopts the Pennes' bioheat transfer equation to mathematically determine the transient temperature distribution across the uterus wall by employing finite integral transforms. Special focus is given to situations in which the temperature of the fluid inside the balloon is no longer constant and may impair the effectiveness of the treatment. On general terms, it was found that the temperature distribution is strongly dependent on the perfusion coefficient and is also significantly affected by the rate of the decay of the fluid temperature inside the balloon.

Keywords: bioheat transfer, integral transform, endometrial ablation

\section{Introduction}

Menorrhagia affects about $30 \%$ of women worldwide throughout the course of their fertile years, and it is considered to be the main reason of complaint in a gynecologist practice. In some cases, this state can present itself in such an adverse way that daily activities cannot be carried out in a proper fashion. From a medical point of view, menorrhagia is technically defined as "the loss of more than $80 \mathrm{ml}$ of blood per menstrual cycle" which may last for more than seven days. On a long range, menorrhagia can lead to an iron-deficiency anemia and, therefore, it is considered to be an important healthcare issue (Oehler and Rees, 2001).

Dysfunctional uterine bleeding can be triggered by many factors. Uterine fibroids, pelvic inflammatory disease, estrogen or progesterone imbalances and high levels of prostaglandins or endothelins are considered to be the main causes of menorrhagia. In some circumstances, liver, kidney or thyroid diseases may, as well, produce an excessive uterine bleeding. Menorrhagia is diagnosed through a series of blood tests in conjunction with an ultrasound, an endometrial biopsy and a hysterescopy, which is a visual examination of the uterine cavity. Once prognosticated, it can be treated by a hormonal therapy, prostaglandin inhibitors and an iron supplementation if the presence of amenia is confirmed. However, such strategies require a long term commitment and may produce side effects. While non hormonal procedures may also be employed, a drug based therapy for the treatment of menorrhagia is often reputed as ineffective (Baldwin et al., 2001).

Surgical means have long been utilized as a way to deal with excessive menstrual bleeding. Until recently, the most prevalent one was hysterectomy, in which the uterus is totally removed. While this procedure grants an almost $100 \%$ rate of success, it is an extremely invasive operation involving high costs together with a slow recovery time. During the last 20 years, less drastic treatments were devised yielding to the concept of endometrial ablation. The various methods of ablating the endometrial layer stem from the observation that the complete destruction of this uterine stratum causes a permanent state of amenorrhea. Consequently, the main purpose of this intervention is to selectively destroy the endometrium beyond the point of regeneration. The thermal balloon ablation method is

Paper accepted January, 2009. Technical Editor: Agenor de T. Fleury particularly well accepted within the medical community, and studies such those of Friberg et al. (1996), Villos et al. (1996) and Buckshee et al. (1998) provide an interesting amount of clinical evidence asserting the effectiveness of this particular therapy. In this technique, a latex balloon filled with $10 \mathrm{ml}$ of a sterile solution at a pressure of approximately $160 \mathrm{~mm} \mathrm{Hg}$ is placed inside the uterine cavity of the patient. A $160 \times 3 \mathrm{~mm}$ plastic catheter connects the balloon to a control unit, which is designed to regulate both the pressure and the temperature of the sterile fluid. A heating element continually raises the temperature of the intraballoon solution to approximately $87{ }^{\circ} \mathrm{C}$ after which both the pressure and temperature are kept constant for the next 8 minutes. During this period, heat is constantly transferred from the balloon to the inner lining of the uterus producing a thermal injury.

It appears that few investigators have attempted to mathematically model the transient temperature distribution through the uterine tissue when subjected to an endometrial ablation. Baldwin et al. (2001) considers the uterus as a planar single region structure and adopts a finite difference solution scheme for the bioheat transfer equation in order to determine the depth of irreversible tissue damage, which is an important parameter in the evaluation of the efficiency of this procedure. The numerical simulations revealed that the effect of the uterine metabolic heat rate can be neglected in the prediction of the temperature field. On the other hand, the degree of injury is significantly affected by the blood flow rate circulating within the uterus. Among their various findings, the authors conclude that the zone of endometrial thermal destruction lies in the range of 3 to $6 \mathrm{~mm}$ which correlates well with experimental data (Singh et al., 2000). Presgrave et al. (2005b) derive an analytical-numerical solution based on integral transform techniques to a generalized bioheat transfer equation in which the endometrial ablation process is studied as a particular application of this more involved model. They employ the same assumptions postulated in Baldwin's work (2001), but due to the particular nature of this example, a fully analytical solution to the thermal balloon endometrial ablation is obtained. As a general comment, the eigenfunction expansion convergence pattern is found to be very fast predicting accurate results for the transient temperature field for some commonly accepted values of the perfusion coefficient.

One basic assumption to both studies is the fact that the temperature of the balloon solution is maintained constant throughout the eight-minute process. Recent work (Reinders et al., 2003) suggests that modern thermal ablation processes are designed 
to incorporate a time varying fluid temperature primarily for safety reasons. Also, if the control unit does not deliver the necessary power to maintain the sterile solution at optimal temperature levels, the performance of the treatment will certainly be diminished. Consequently, this contribution is aimed at studying an endometrial ablation process in cases in which the intraballoon solution experiences a prescribed temporal decay. As it shall be demonstrated in the following sections, the mathematical formulation to this new problem is analytically handled through integral transform methodologies with the intent of obtaining a correlation for the depth of the thermal injury as a function of both the temperature decay and the uterine blood flow rate.

\section{Nomenclature}

$$
\begin{aligned}
A & =\text { Frequency factor, } s^{-1} \\
A_{i} & =\text { Coefficients of the eigenfunction expansion } \\
b & =\text { Rate of decay of the intraballoon solution, } s^{-1} \\
C & =\text { Specific heat, } \mathrm{J} / \mathrm{kg}{ }^{\circ} \mathrm{C} \\
C_{i} & =\text { Coefficients of the eigenfuntion expansion } \\
i & =\text { Summation index } \\
k & =\text { Thermal conductivity, } \mathrm{W} / \mathrm{m}{ }^{\circ} \mathrm{C} \\
l & =\text { Uterus thickness, } m \\
l_{\text {dam }} & =\text { Depth of the affected uterine tissue, } m \\
N_{i} & =\text { Norm related to eigenvalue " } i \text { " } \\
P_{f} & =\text { Dimensionless perfusion coefficient } \\
R & =\text { Universal gas constant, } J \text { mol }{ }^{-1} \mathrm{~K}^{-1} \\
T & =\text { Time, } s \\
T & =\text { Temperature, }{ }^{\circ} \mathrm{C} \\
T_{b} & =\text { Arterial blood temperature, }{ }^{\circ} \mathrm{C} \\
T_{\text {final }} & =\text { Temperature of the intraballoon solution at the end of the } \\
& \text { treatment, }{ }^{\circ} \mathrm{C} \\
T_{\text {ref }} & =\text { Reference temperature for the intraballoon solution, }{ }^{\circ} \mathrm{C} \\
x & =\text { Dimensional space variable, } m
\end{aligned}
$$

\section{Greek Symbols}

$\beta=$ Dimensionless rate of decay of the intraballoon solution

$\Delta E=$ Activation energy for burn reaction, $\mathrm{J} \mathrm{mol}^{-1}$

$\theta_{\text {aux }}=$ Dimensionless auxiliary temperature

$\theta_{h}=$ Dimensionless homogeneous temperature distribution

$\bar{\theta}_{\mathrm{i}}=$ Transformed temperature field

$\mu_{i}=$ Eigenvalue of order " $i$ "

$\rho=$ Density, $\mathrm{kg} / \mathrm{m}^{3}$

$\tau=$ Dimensionless time variable

$\chi=$ Dimensionless space variable

$\Psi_{I}=$ Eigenfunction related to eigenvalue " $i$ "

$\omega=$ Blood perfusion rate, $m_{b}^{3} m^{-3} s^{-1}$

$\Omega=$ Cumulative damage integral

\section{Subscripts \\ b Blood \\ i Summation index}

\section{Analysis}

The starting point of the mathematical model that describes the transient temperature field through the uterine wall is the so-called Pennes' bioheat model. This equation was first derived in connection with temperature measurements in the resting forearms of adults (Pennes, 1948), and since then it has been utilized to study several interesting situations in medical related applications such as tumor treatments (Azevedo, 2004; Azevedo et al., 2006), burn injuries and selective brain cooling (Presgrave et al., 2006, 2007b).
In essence, the bioheat transfer equation can be regarded as a standard diffusion equation with an extra contribution that accounts for the heat removal due to the blood flow in the organic tissue. In the present application, the uterus wall is considered as a planar structure whose thickness is taken as 1 . Considering a onedimensional transient, constant property situation, the bioheat transfer equation for this specific case can be written as:

$\rho C \frac{\partial T(x, t)}{\partial t}=k \frac{\partial^{2} T(x, t)}{\partial x^{2}}-\varpi \rho_{b} C_{b}\left(T(x, t)-T_{b}\right) 0<x<1, t>01$

where $\rho_{b}, C_{b}, T_{b}$ and $\varpi$ are, respectively, the density, specific heat, arterial temperature and the perfusion rate of the blood. The other variables have their usual significance and refer to tissue related quantities. Consistent with previous studies (Presgrave et al., 2006, 2007a), the initial temperature distribution in biological problems is usually supposed to be uniform and equal to the arterial temperature of the blood. Therefore:

$$
\mathrm{T}(\mathrm{x}, 0)=\mathrm{T}_{\mathrm{b}}, 0 \leq \mathrm{x} \leq 1
$$

Another common trait in the mathematical modeling of thermal balloon endometrial ablation is to consider that the outer layer of the uterus wall is in perfect thermal contact with the fluid inside the balloon (Baldwin et al., 2001). Moreover, in this study attention is focused in cases in which the fluid temperature experiences a prescribed temporal decay. Accordingly, the boundary condition at the outer wall is considered to be:

$$
\mathrm{T}(0, \mathrm{t})=\mathrm{T}_{\mathrm{b}}+\left(\mathrm{T}_{\mathrm{ref}}-\mathrm{T}_{\mathrm{b}}\right) \mathrm{e}^{-\mathrm{bt}}, \mathrm{t}>0
$$

where $T_{\text {ref }}$ is a suitable reference temperature and $b$ is a coefficient related to rate of temperature decay of the fluid. Finally, an insulated boundary condition at the uterus inner wall is assumed (Presgrave, 2005a) and thus:

$$
\frac{\partial \mathrm{T}(1, \mathrm{t})}{\partial \mathrm{x}}=0, \mathrm{t}>0
$$

At this point, it is worth mentioning that the rate of metabolic heat generation inside the uterus is not present in the above formulation. In fact, previous studies, Baldwin et al. (2001), Presgrave (2005a) and Presgrave et al. (2005b) have conclusively demonstrated that the metabolic heat plays a minor role in this physical situation and can be safely abandoned in the thermal balance equation.

Now, Equations (1) - (4) are written in a dimensionless form by employing the following variables:

$$
\chi=\frac{\mathrm{x}}{1}, \tau=\frac{\mathrm{k}}{\rho \mathrm{C}} \frac{\mathrm{t}}{1^{2}}, \theta=\frac{\mathrm{T}-\mathrm{T}_{\mathrm{b}}}{\mathrm{T}_{\mathrm{ref}}-\mathrm{T}_{\mathrm{b}}}
$$

Accordingly, it is relatively easy to find that the dimensionless mathematical formulation for the problem addressed is:

$$
\begin{aligned}
& \frac{\partial \theta(\chi, \tau)}{\partial \tau}=\frac{\partial^{2} \theta(\chi, \tau)}{\partial \chi^{2}}-P_{f} \theta(\chi, \tau), 0<\chi<1, \tau>0 \\
& \theta(\chi, 0)=0,0 \leq \chi \leq 1
\end{aligned}
$$




$$
\theta(0, \tau)=\mathrm{e}^{-\beta \tau} ; \frac{\partial \theta(1, \tau)}{\partial \chi}=0, \tau>0
$$

Here, $P_{f}$ and $\beta$ are, respectively, the dimensionless perfusion coefficient and rate of decay of the temperature of the fluid inside the endometrial balloon. Their definitions are given by:

$$
\mathrm{P}_{\mathrm{f}}=\frac{\varpi \rho_{\mathrm{b}} \mathrm{C}_{\mathrm{b}} 1^{2}}{\mathrm{k}}, \beta=\frac{\mathrm{b} \rho \mathrm{C} 1^{2}}{\mathrm{k}}
$$

This formulation can be viewed as a particular case of the "class I" category, Mikhailov and Ozisik (1984), and consequently a solution to the temperature distribution can be sought in terms of an eigenfuction expansion. Thus, the dimensionless temperature field can be expressed as:

$$
\theta(\chi, \tau)=\sum_{\mathrm{i}=1}^{\infty} \mathrm{A}_{\mathrm{i}}(\tau) \psi_{\mathrm{i}}(\chi)
$$

where the eigenfunctions $\psi_{i}(\chi)$ are related to the following eigenproblem:

$$
\begin{aligned}
& \frac{\mathrm{d}^{2} \psi_{\mathrm{i}}(\chi)}{\mathrm{d} \chi^{2}}+\mu_{\mathrm{i}}^{2} \psi_{\mathrm{i}}(\chi)=0,0<\chi<1 \\
& \psi_{\mathrm{i}}(0)=0, \frac{\mathrm{d} \psi_{\mathrm{i}}(1)}{\mathrm{d} \chi}=0
\end{aligned}
$$

It is a simple matter to show that the eigenquantities such as the eigenfuctions, the norm and the eigenvalues are determined as:

$$
\psi_{\mathrm{i}}(\chi)=\sin \left(\mu_{\mathrm{i}} \chi\right), \mathrm{N}_{\mathrm{i}}=\frac{1}{2}, \mu_{\mathrm{i}}=\frac{2 \mathrm{i}-1}{2} \pi
$$

By utilizing the orthogonality property of the regular SturmLiouville problems, we find that:

$$
\mathrm{A}_{\mathrm{i}}(\tau)=\frac{1}{\mathrm{~N}_{\mathrm{i}}} \int_{0}^{1} \psi_{\mathrm{i}}(\chi) \theta(\chi, \tau) \mathrm{d} \chi
$$

and the transform-inverse pair is established as:

$$
\begin{aligned}
& \bar{\theta}_{\mathrm{i}}(\tau)=\frac{1}{\mathrm{~N}_{\mathrm{i}}^{1 / 2}} \int_{0}^{1} \psi_{\mathrm{i}}(\chi) \theta(\chi, \tau) \mathrm{d} \chi \\
& \theta(\chi, \tau)=\sum_{\mathrm{i}=1}^{\infty} \frac{1}{\mathrm{~N}_{\mathrm{i}}^{1 / 2}} \psi_{\mathrm{i}}(\chi) \bar{\theta}_{\mathrm{i}}(\tau)
\end{aligned}
$$

At this point, a series of mathematical manipulations, which are well documented in Cotta (1993) and Cotta (1998) are utilized to rewrite the original problem, Eqs. (8) - (11), in terms of the transformed variable $\bar{\theta}_{\mathrm{i}}(\tau)$. Basically, Eq (8) is operated on with
$\frac{1}{\mathrm{~N}_{\mathrm{i}}^{1 / 2}} \int_{0}^{1} \psi_{\mathrm{i}}(\chi) \mathrm{d} \chi$,

while relation (15) is handled through

$\frac{1}{\mathrm{~N}_{\mathrm{i}}^{1 / 2}} \int_{0}^{1} \theta(\chi, \tau) \mathrm{d} \chi$

These two results are combined, and with the aid of the boundary conditions of both the temperature field and chosen eigenvalue problem, the following ordinary differential equations for $\bar{\theta}_{i}(\tau)$ are determined:

$$
\frac{\mathrm{d} \bar{\theta}_{\mathrm{i}}(\tau)}{\mathrm{d} \tau}+\left(\mu_{\mathrm{i}}^{2}+\mathrm{P}_{\mathrm{f}}\right) \bar{\theta}_{\mathrm{i}}(\tau)=\frac{1}{\mathrm{~N}_{\mathrm{i}}^{1 / 2}} \mu_{\mathrm{i}} \mathrm{e}^{-\beta \tau}
$$

The transform relation is applied to Eq. (9) furnishing the initial conditions for the above system:

$$
\bar{\theta}_{\mathrm{i}}(0)=0
$$

Due to the decoupled nature of Eq. (24), an analytical solution for the transformed dimensionless temperature field is immediately established as:

$$
\bar{\theta}_{\mathrm{i}}(\tau)=\frac{1}{\mathrm{~N}_{\mathrm{i}}^{1 / 2}} \frac{\mu_{\mathrm{i}}}{\mu_{\mathrm{i}}^{2}+\mathrm{P}_{\mathrm{f}}+\beta}\left[\mathrm{e}^{-\beta \tau}-\mathrm{e}^{-\left(\mu_{\mathrm{i}}^{2}+\mathrm{P}_{\mathrm{f}}\right) \tau}\right]
$$

and utilizing the inverse relation, Eq. (23), the transient temperature distribution across the uterus wall is:

$$
\begin{aligned}
& \theta(\chi, \tau)=2 \sum_{\mathrm{i}=1}^{\infty} \frac{\mu_{\mathrm{i}}}{\mu_{\mathrm{i}}^{2}+\mathrm{P}_{\mathrm{f}}-\beta} \sin \left(\mu_{\mathrm{i}} \chi\right) \mathrm{e}^{-\beta \tau} \\
& -2 \sum_{\mathrm{i}=1}^{\infty} \frac{\mu_{\mathrm{i}}}{\mu_{\mathrm{i}}^{2}+\mathrm{P}_{\mathrm{f}}-\beta} \sin \left(\mu_{\mathrm{i}} \chi\right) \mathrm{e}^{-\left(\mu_{\mathrm{i}}^{2}+\mathrm{P}_{\mathrm{f}}\right) \tau}
\end{aligned}
$$

An inspection of the first term in the expression above suggests that its convergence characteristics are expected to be poor since the proposed eigenvalue problem cannot incorporate the exponential decay shown in Eq. (10). As a consequence, the direct application of this relation does not recover the time varying boundary condition at $\chi=0$ and perhaps it may not furnish precise results for uterine regions close the application of the endometrial balloon. Since one of the main goals of this research is to predict accurate temperature fields for the endometrial region $(0<\mathrm{x}<4 \mathrm{~mm})$, an alternative solution scheme appears to be desirable. Here, in accordance with Mikhailov and Ozisik (1984), a "split-up" procedure is employed in which the dimensionless temperature field is regarded as the sum of an auxiliary term together with a homogenous problem in such a way that:

$$
\theta(\chi, \tau)=\theta_{\text {aux }}(\chi) \mathrm{e}^{-\beta \tau}+\theta_{\mathrm{h}}(\chi, \tau)
$$


where the problem for $\theta_{\text {aux }}(\chi)$ is taken as:

$$
\begin{aligned}
& \frac{\mathrm{d}^{2} \theta_{\mathrm{aux}}(\chi)}{\mathrm{d} \chi^{2}}+\left(\beta-\mathrm{P}_{\mathrm{f}}\right) \theta_{\mathrm{aux}}(\chi)=0,0<\chi<1 \\
& \theta_{\text {aux }}(0)=1, \frac{\mathrm{d} \theta_{\mathrm{aux}}(1)}{\mathrm{d} \chi}=0
\end{aligned}
$$

By inserting relation (28) in Eqs. (8) - (11), the formulation that governs $\theta_{\mathrm{h}}(\chi, \tau)$ is found to be:

$$
\begin{aligned}
& \frac{\partial \theta_{\mathrm{h}}(\chi, \tau)}{\partial \tau}=\frac{\partial^{2} \theta_{\mathrm{h}}(\chi, \tau)}{\partial \chi^{2}}+\mathrm{P}_{\mathrm{f}} \theta(\chi, \tau), 0<\chi<1, \tau>0 \\
& \theta_{\mathrm{h}}(\chi, 0)=-\theta_{\text {aux }}(\chi), 0 \leq \chi \leq 1 \\
& \theta_{\mathrm{h}}(0, \tau)=0, \frac{\partial \theta_{\mathrm{h}}(1, \tau)}{\partial \chi}=0, \tau>0
\end{aligned}
$$

Due to the now homogenous nature of this problem, its solution can also be determined with the aid of eigenfunction expansion techniques. By utilizing the same eigenvalue problem described in relations $(15)-(17)$, it is a straightforward matter to conclude that:

$$
\theta_{\mathrm{h}}(\chi, \tau)=\sum_{\mathrm{i}=1}^{\infty} \mathrm{C}_{\mathrm{i}} \psi_{\mathrm{i}}(\chi) \mathrm{e}^{-\left(\mu_{\mathrm{i}}^{2}+\mathrm{P}_{\mathrm{f}}\right) \tau}
$$

The constants $C_{i}$ are determined by the orthogonality property of the Sturm-Liouville problem and some standard manipulations of Eqs. (29) - (31) reveal that:

$$
C_{i}=-\frac{1}{N_{i}} \int_{0}^{1} \theta_{a u x}(\chi) \psi_{i}(\chi) d \chi=\frac{-2 \mu_{i}}{\mu_{i}^{2}+\left(P_{f}-\beta\right)}
$$

Finally, in order to fully establish this second solution scheme, the problem for $\theta_{\text {aux }}(\chi)$ must be addressed. An inspection of Eqs. (29) - (31) indicates that three different cases can be envisioned:

$$
\begin{aligned}
& \theta_{\text {aux }}(\chi)=1, \text { for } \mathrm{P}_{\mathrm{f}}-\beta \approx 0 \\
& \theta_{\text {aux }}(\chi)=\cosh (\gamma \chi)-\tanh (\gamma) \sinh (\gamma \chi), \\
& \gamma=\sqrt{\mathrm{P}_{\mathrm{f}}-\beta} \text {,for } \mathrm{P}_{\mathrm{f}}-\beta>0 \\
& \theta_{\text {aux }}(\chi)=\tan (\mathrm{m}) \sin (\mathrm{m} \chi)+\cos (\mathrm{m} \chi) \\
& \mathrm{m}=\sqrt{\beta-\mathrm{P}_{\mathrm{f}}}, \text { for } \mathrm{P}_{\mathrm{f}}-\beta<0
\end{aligned}
$$

\section{Results and Discussion}

Having derived two solution schemes for the endometrial ablation problem, we are now in a position to explore the relative merits of these procedures and also to study the effect of the temperature decay of the fluid inside the balloon in the performance of the treatment. Throughout the various numerical simulations performed, the set of data described in Table 1 were utilized:

An inspection of Table 1 shows that three different values of the blood perfusion rate are employed in this research. Actually, the normal value for the uterine blood perfusion rate is reported to be

\begin{tabular}{|c|c|c|c|}
\hline Parameter & Description & Units & Values \\
\hline$\varpi$ & $\begin{array}{l}\text { Rate of blood } \\
\text { perfusion }\end{array}$ & $\mathrm{m}_{\mathrm{b}}^{3} \mathrm{~m}^{-3} \mathrm{~s}^{-1}$ & $\begin{array}{c}0.0014,0.0028, \\
0.0056\end{array}$ \\
\hline $\mathrm{k}$ & $\begin{array}{c}\text { Thermal conductivity - } \\
\text { uterus }\end{array}$ & $\mathrm{W} \mathrm{m}^{-1}{ }^{\circ} \mathrm{C}^{-1}$ & 0.56 \\
\hline $\mathrm{C}$ & Specific heat - uterus & $\mathrm{J} \mathrm{kg}^{-1} \mathrm{C}^{-1}$ & 3600 \\
\hline $\mathrm{C}_{\mathrm{b}}$ & Specific heat - blood & $\mathrm{J} \mathrm{kg}^{-1} \mathrm{C}^{-1}$ & 3500 \\
\hline$\rho$ & Density - uterus & $\mathrm{kg} \mathrm{m}^{-3}$ & 1060 \\
\hline$\rho_{b}$ & Density - blood & $\mathrm{kg} \mathrm{m}^{-3}$ & 1080 \\
\hline $\mathrm{T}_{\mathrm{b}}$ & $\begin{array}{l}\text { Arterial blood } \\
\text { temperature }\end{array}$ & $\mathrm{C}$ & 37 \\
\hline 1 & Thickness - uterus & $\mathrm{mm}$ & 20 \\
\hline $\mathrm{b}$ & $\begin{array}{l}\text { Rate of decay - fluid } \\
\text { temperature }\end{array}$ & $\mathrm{s}^{-1}$ & $0-8.15 \times 10^{-3}$ \\
\hline $\mathrm{T}_{\mathrm{ref}}$ & $\begin{array}{l}\text { Reference temperature } \\
\text { - intraballoon fluid }\end{array}$ & $\mathrm{C}$ & 87 \\
\hline$T_{\text {final }}$ & Final fluid temperature & $\mathrm{C}$ & $37-87$ \\
\hline $\mathrm{A}$ & Frequency factor & $\mathrm{s}^{-1}$ & $5.6 \times 10^{63}$ \\
\hline$\Delta \mathrm{E}$ & $\begin{array}{l}\text { Activation energy for } \\
\text { burn reaction }\end{array}$ & $\mathrm{J} \mathrm{mol}^{-1}$ & $4.3 \times 10^{5}$ \\
\hline $\mathrm{R}$ & Universal gas constant & $\mathrm{J} \mathrm{mol}^{-1} \mathrm{~K}^{-1}$ & 8.314 \\
\hline
\end{tabular}
around $0.0028 \mathrm{~m}_{\mathrm{b}}^{3} \mathrm{~m}^{-3} \mathrm{~s}^{-1}$ (Baldwin et al., 2001). The other two values are considered in order to establish the sensitivity of the mathematical model regarding the perfusion coefficient and, at the same time, to gain some insight in two interesting phenomena associated to the problem in question. One is hyperemia, which can be briefly described as the increase of blood flow in response to thermal injuries suffered by an organic tissue. The other phenomenon refers to a decrease in the perfusion effects caused by a possible occlusion of the vessels due to an elevated pressure inside the balloon.

Table 1. Parameter values employed in the numerical simulations.

Another important aspect refers to the evaluation of the coefficient $b$. In this research, the temperature of the intraballoon solution is supposed to decay with time at an exponential rate and, if we further assume that the temperature at the end of the eight minute treatment, $T_{\text {final }}$, is available, the coefficient $b$ is determined as:

$$
\mathrm{b}=-\frac{1}{480} \ln \left(\frac{\mathrm{T}_{\text {final }}-\mathrm{T}_{\mathrm{b}}}{\mathrm{T}_{\text {ref }}-\mathrm{T}_{\mathrm{b}}}\right)
$$

Finally, the last three parameters in Table 1 pertain to the socalled cumulative damage integral, $\Omega(\mathrm{x}, \mathrm{t})$ :

$$
\Omega(\mathrm{x}, \mathrm{t})=\mathrm{A} \int_{0}^{\mathrm{t}} \exp \left(-\frac{\Delta \mathrm{E}}{\mathrm{R} T(\mathrm{x}, \mathrm{t})}\right) \mathrm{dt}
$$

which is often used to model the penetration of thermal injury in biological bodies. According to Baldwin et al. (2001), the first signs of irreversible damage are predicted to occur whenever $\Omega(x, t)$ is around unity and this criterion will be utilized in our study to determine the extent of the affected uterine tissue at any given situation. 
The first aspect to be addressed is the performance of the two proposed methodologies for the solution of the mathematical model to the endometrial ablation therapy. On general grounds, it was observed that the "split-up" solution, Eq. (28), exhibits a very fast convergence rate and for the numerical simulations studied here, a 10 term expansion is found to be sufficient enough to warrant graphical convergence. As for the "direct" eigenfuction expansion approach, the convergence patterns were not so rapid. Perhaps, this characteristic can be better envisioned by examining Figs. 1 and 2, where a comparison between these two procedures is performed and is related to a severe temperature drop of $40{ }^{\circ} \mathrm{C}\left(\mathrm{T}_{\text {final }}=47^{\circ} \mathrm{C}\right)$.

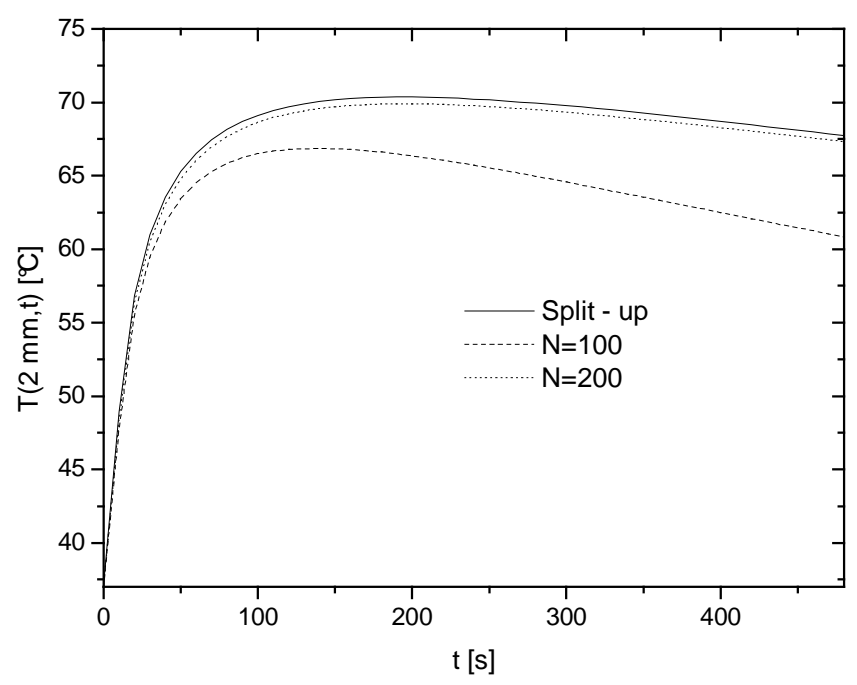

Figure 1. Converged split-up solution versus direct solution: $T_{\text {final }}=47^{\circ} \mathrm{C}$, $\boldsymbol{\sigma}=0.0028 \mathrm{~m}_{\mathrm{b}}^{3} \mathrm{~m}^{-3} \mathrm{~s}^{-1}$.

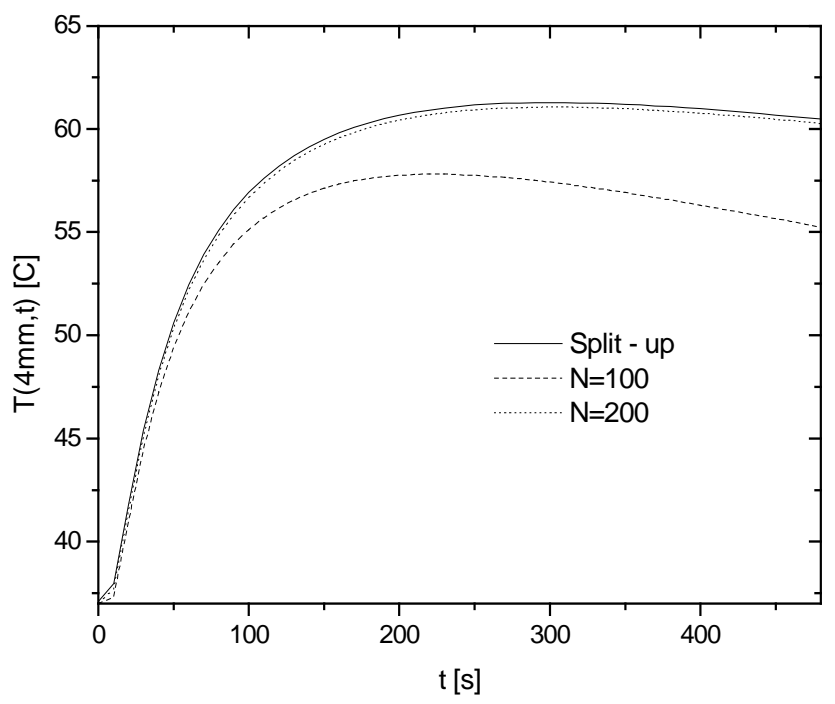

Figure 2. Converged split-up solution versus direct solution: $\mathrm{T}_{\text {final }}=47^{\circ} \mathrm{C}$, $\bar{\sigma}=0.0028 \mathrm{~m}_{\mathrm{b}}^{3} \mathrm{~m}^{-3} \mathrm{~s}^{-1}$.
Since accurate predictions at the endometrial region are important for the determination of the efficacy of the treatment, Fig. 1 presents the temperature distribution at the midplane of the endometrium, while Fig. 2 performs the same study at the base of the endometrium. As previously anticipated, an expansion up to 200 terms in the "direct" solution provides only poor graphically converged results at both regions. This slow convergence pattern is associated to the rapidly varying temperature of the fluid inside the balloon that cannot be taken into account in the eigenvalue problem, and therefore, it is no surprise that these results are not converged especially at times around the peak value of the temperature field. Since this trend was observed all throughout the simulations, we can safely affirm that the predictions related to Eq. (27) should be discarded in favor of the more numerically accurate solution represented by relation (28), and accordingly, all further results are based on the "split-up" procedure exclusively.

A qualitative inspection of the importance associated to the temperature variation of the fluid inside the endometrial balloon can be examined in Figs. 3 and 4 where all the simulations refer to the accepted standard value for the uterine blood flow rate $(\varpi=0.0028$ $\mathrm{m}_{\mathrm{b}}^{3} \mathrm{~m}^{-3} \mathrm{~s}^{-1}$ ). During the early stages of the transient process, both figures reveal that the temperature profile at the midplane and at the base of the endometrium layer is virtually unaffected by the temperature variation of the fluid. However, as times progresses, the various curves related to a specific temperature drop deviate from one another. Studies in burn injuries argue that temperatures in the range of $42{ }^{\circ} \mathrm{C}<\mathrm{T}<55^{\circ} \mathrm{C}$ produce some degree of damage which is, in certain cases, reversible depending on the total time exposure to the heat source. Conversely, when tissue temperatures are in excess of $55^{\circ} \mathrm{C}$, thermal damage becomes increasingly irreversible (Presgrave et al., 2006). Using this broad criterion and keeping in mind that the main purpose of the treatment is to produce permanent tissue damage across the whole of the endometrium layer, Figs. 3 and 4 suggest that in order to achieve this target the temperature drop should not be very pronounced.

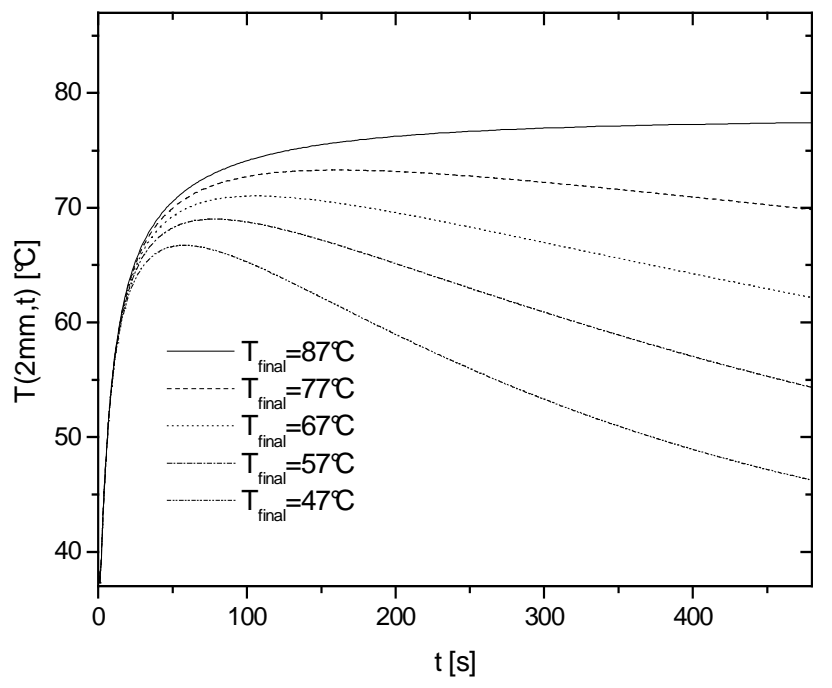

Figure 3. Temperature distributions at the midplane of the endometrium layer: $\omega=0.0028 \mathrm{~m}_{\mathrm{b}}^{3} \mathrm{~m}^{-3} \mathrm{~s}^{-1}$. 


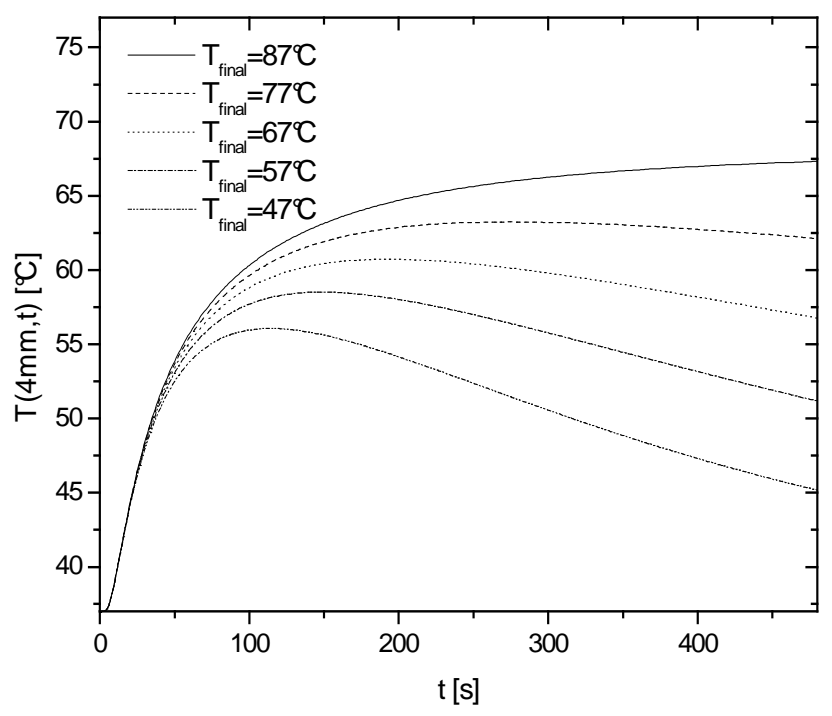

Figure 4. Temperature distributions at the base of the endometrium layer: $\bar{\sigma}=0.0028 \mathrm{~m}^{3} \mathrm{~m}^{-3} \mathrm{~s}^{-1}$.

For example, an examination of Fig. 3 shows that the midplane of the endometrium remains at temperatures above $55^{\circ} \mathrm{C}$ for only $\mathrm{T}_{\text {final }}>57{ }^{\circ} \mathrm{C}$. Nonetheless, Fig. 4 indicates that in order to the treatment to be effective, the temperature drop should not be below $20{ }^{\circ} \mathrm{C}\left(\mathrm{T}_{\text {final }}=67^{\circ} \mathrm{C}\right)$.

Control of the serosal temperature distribution is also a key factor in the endometrial ablation treatment. Even though no clear medical specifications seem to be available regarding maximum levels at the serosal layer, some researchers suggest that the temperatures at this particular region are not supposed to remain above $42{ }^{\circ} \mathrm{C}$ in the sense that internal organs adjacent to the inner layer of the uterus should be protected from heat sources (Buckshee et al., 1998). Figure 5 presents the transient distribution at the base of the serosal layer $(20 \mathrm{~mm})$ for certain values of the final fluid temperature.

Initially, it can be noticed that for approximately half of the total time treatment $(240 \mathrm{~s})$, the temperature rise experienced by the serosal layer is minimum and does not seem to be significantly influenced by the values of $\mathrm{T}_{\text {final }}$. As expected, towards the end of the treatment, the effects associated to the temperature variation of the fluid become more noticeable. However, even for the most severe situation $\left(\mathrm{T}_{\text {final }}=87^{\circ} \mathrm{C}\right)$, the final temperature is below the $42{ }^{\circ} \mathrm{C}$ threshold, indicating that the safety criterion has been matched. It should be noted that in this simulation a zero flux boundary condition is considered at this location, while Baldwin et al. (2001) adopts a prescribed temperature equal to that of the arterial blood flow. Consequently, the actual serosal temperature is expected to be lower compared to the results in Fig. 5, since the boundary condition adopted here naturally furnishes an upper bound.

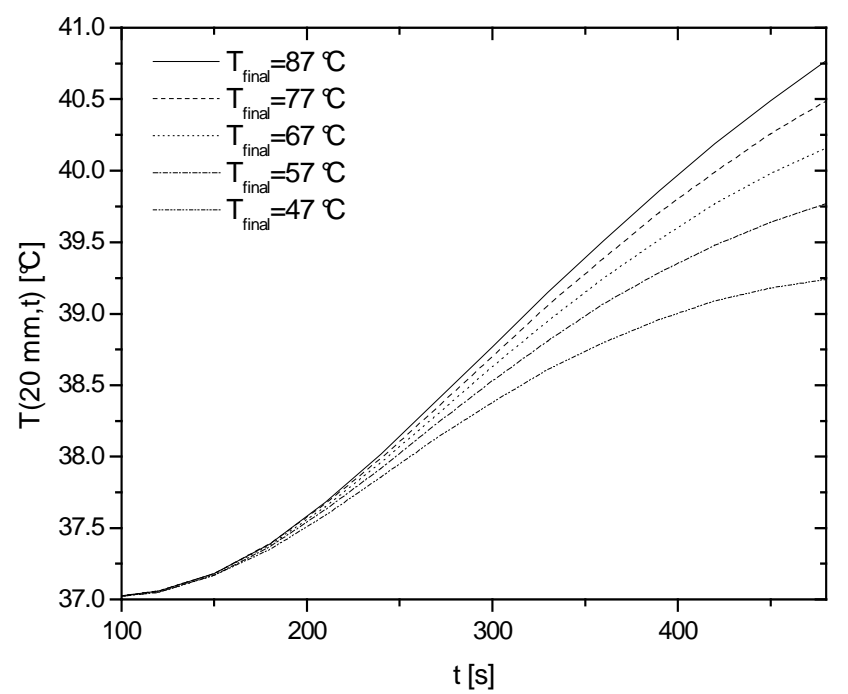

Figure 5. Temperature distribution at the base of the serosal layer: $\boldsymbol{\sigma}=$ $0.0028 \mathrm{~m}^{3} \mathrm{~m} \mathrm{~m}^{-3} \mathrm{~s}^{-1}$.

Figure 6 presents an evaluation of the extent of the damaged uterine tissue, $1_{\text {dam }}$, as a function of both the final fluid temperature and to the perfusion coefficient. These results are obtained by employing the damage integral defined in Eq. (42), and are numerically estimated by the trapezoidal rule utilizing time intervals of $1 \mathrm{~s}$ through the eight-minute treatment. Moreover, the same criterion established by Baldwin et al. (2001) is adopted here and therefore this damage length refers to cases in which $\Omega\left(l_{\text {dam }}, 8 \mathrm{~min}\right) \cong 1$. A closer examination of the data presented in Fig. 6 reveals some interesting features. As expected, the final temperature of the fluid inside the balloon is critical to assess the efficiency of the treatment as only small temperature drops will be able to affect a significant portion of the $4 \mathrm{~mm}$ targeted length.

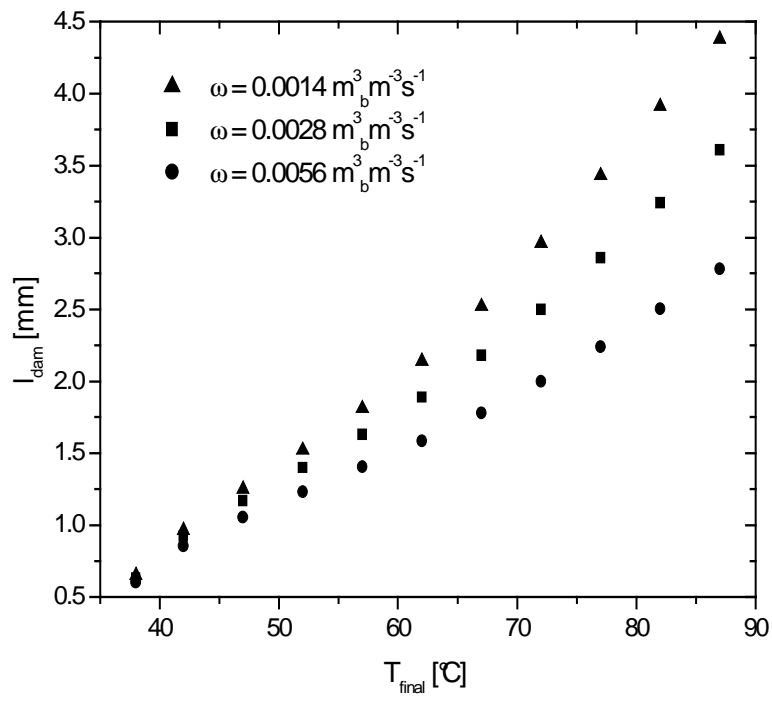

Figure 6. Depth of the affected uterine tissue as a function of $T_{\text {final }}$ and the perfusion coefficient. 
Also, it can be observed that for extreme temperature drops, which correspond to the lower values of $\mathrm{T}_{\text {final }}$, the rate of blood perfusion appears to play a minor role in the determination of the affected uterine tissue. On the other hand, as this temperature drop becomes less pronounced, variations of the perfusion coefficient significantly influence the degree of the thermal injury. For example, if the results associated to a 10 degree drop $\left(\mathrm{T}_{\text {final }}=77^{\circ} \mathrm{C}\right)$ are examined, one finds that the damaged lengths related to the three perfusion coefficients considered in this study are 2.24, 2.86 and $3.43 \mathrm{~mm}$ which indicates a $53 \%$ deviation between the two extreme values. In reality, this aspect is a direct consequence of the Pennes' model, where the effect of the blood flow in an organic tissue is assumed to be directly proportional to the difference between the local temperature field and that of the arterial blood. Therefore, in situations related to values of $\mathrm{T}_{\text {final }}$ slightly above $37{ }^{\circ} \mathrm{C}$, the perfusion effect is naturally quite small regardless of the magnitude of $\varpi$. At this point, it should also be mentioned that for the zero temperature drop situation $\left(b=0\right.$ or $T_{\text {final }}=87^{\circ} \mathrm{C}$ ), the values of the damage integral obtained here are practically coincident with those reported by Baldwin et al. (2001) whose simulations take into account a prescribed temperature at the inner layer of the uterus. As the work reported in this contribution adopts a zero flux boundary condition, Eq. (4), one can infer that, on practical grounds, the present thermal problem could also be handled through analytical techniques that deal with heat diffusion in a semi-infinite medium.

Another aspect of these results is the fact that for a fixed final temperature of the fluid inside the balloon, low values of $\mathrm{P}_{\mathrm{f}}$ yield higher lengths for the damaged uterine tissue, while the simulations associated to the more elevated perfusion coefficient affect a smaller portion of the endometrium. This trend can be anticipated if one perceives the contribution of the blood flow rate as a "sink term" in the mathematical formulation of this problem, $\mathrm{Eq}$ (1). Consequently, an increase of the perfusion coefficient results in less heat available for the burn injury to progress decreasing the depth of the affected tissue. This observation corroborates the need for experimental protocols regarding the accurate evaluation of the rate of blood flow in the uterine tissue especially in cases where hyperemia and occlusion are relevant.

\section{Conclusion}

In summary, the present contribution is aimed at studying the transient temperature field of across a uterus when subjected to an ablation process carried out by an endometrial balloon. More specifically, the main purpose of this research is to assess the effectiveness of the treatment in cases where the temperature of the fluid inside the balloon decays exponentially throughout the eightminute therapy. For this purpose, a mathematical model was devised and two fully analytical solution schemes were presented. An examination of the convergence rate for both procedures was presented and it became apparent that the "split-up" approach should be used as it furnishes more accurate results with very few expansion terms. A criterion to evaluate the depth of thermal injury was employed and the numerical simulations revealed that the perfusion coefficient plays an important role in the evaluation of this quantity, particularly in cases related to small temperature drops.

As a closing remark, the results depicted in Fig. 6 suggest that for a fixed blood flow rate, the dependence between the final temperature of the fluid inside the endometrial balloon and the depth of the affected uterine tissue is reasonably well represented by a linear relation. By performing a least square fit, one finds:

$$
\begin{aligned}
& 1_{\text {dam }}=0.07747 \mathrm{~T}_{\text {final }}-2.30267, \Phi=0.0014 \mathrm{~m}_{\mathrm{b}}^{3} \mathrm{~m}^{-3} \mathrm{~s}^{-1} \\
& 1_{\text {dam }}=0.05869 \mathrm{~T}_{\text {final }}-1.64117, \Phi=0.0028 \mathrm{~m}_{\mathrm{b}}^{3} \mathrm{~m}^{-3} \mathrm{~s}^{-1} \\
& 1_{\text {dam }}=0.04211 \mathrm{~T}_{\text {final }}-0.97494, \Phi=0.0056 \mathrm{~m}_{\mathrm{b}}^{3} \mathrm{~m}^{-3} \mathrm{~s}^{-1}
\end{aligned}
$$

Considering that the thickness of the endometrium layer actually varies from patient to patient and that it can be estimated by a transvaginal ultrasound scanning, perhaps a physician or a design engineer concerned with safety aspects of the uterine endometrial ablation will appreciate these simple expressions that predict the length, in millimeters, of the affected uterine tissue for final balloon fluid temperatures in the range of $37^{\circ} \mathrm{C}<\mathrm{T}_{\text {final }}<87^{\circ} \mathrm{C}$.

\section{References}

Azevedo, M.D.B., 2004, "Analytical numerical simulation of the bioheat transfer in organic tissues" (in Portuguese), Master of Sciences Dissertation, Instituto Militar de Engenharia, Rio de Janeiro, RJ, Brazil, 252p.

Azevedo, M.D.B., Guedes, R.O.C. and Scofano Neto, F., 2006, "Analytical solution to the two-dimensional transient bioheat equation with convective boundary conditions", Proceedings of the 11th Brazilian Congress of Thermal Sciences and Engineering, ABCM, Curitiba, PR, Brazil.

Baldwin, S.A., Perlman, A. and Bert, J.L., 2001, "A heat transfer model of thermal balloon endometrial ablation", Annals of Biomedical Engineering, Vol. 29, pp. 1009-1018.

Buckshee, K., Banerjee, K. and Bhatla, H., 1998, "Uterine balloon therapy to treat menorrhagia", International Journal of Gynaecology and Obstetrics, Vol. 63, pp. 139-143.

Cotta, R.M., 1993, "Integral Transforms in Computational Heat and Fluid Flow", CRC Press, Florida, 340 p.

Cotta, R.M. (ed.), 1998, "The Integral Transform Method in Thermal and Fluids Science and Engineering", Begell House, New York, 430 p.

Friberg, B., Persson, B.R.R., Willen, R. and Ahlgreen, M., 1996, "Endometrial destruction by hyperthermia - a possible treatment for menorrhagia", Acta Obstetricia Gynecologica Scandinavica, Vol. 75, pp. 330- 335 .

Mikhailov, M.D. and Özisik, M.N., 1984, "Unified Analysis and Solutions of Heat and Mass Diffusion”, Dover Publications, New York, 458p.

Oehler, M.K. and Ress, M.C.P., 2003, "Menorrhagia: an update", Acta Obstetricia Gynecologica Scandinavica, Vol. 82, pp. 405- 422.

Pennes, H.H., 1948, "Analysis of tissue and arterial blood temperatures in the resting human Ffrearm", Journal of Applied Physiology, Vol. 1, pp. 93-122.

Presgrave, A.V., 2005a, "Modelling and simulation of blood perfusion effects in bioheat transfer problems" (in Portuguese), Master of Sciences Dissertation, Instituto Militar de Engenharia, Rio de Janeiro, RJ, Brazil, 205p.

Presgrave, A.V., Guedes, R.O.C. and Scofano Neto, F., 2005b, "Hybrid analytical numerical solution to the bioheat transfer equation", Proceedings of the 18th International Congress of Mechanical Engineering, ABCM, Ouro Preto, MG, Brazil.

Presgrave, A.V., Guedes, R.O.C. and Scofano Neto, F., 2006, "Analysis of skin burn injuries through integral transform techniques", Proceedings of the 11th Brazilian Congress of Thermal Sciences and Engineering, ABCM, Curitiba, PR, Brazil.

Presgrave, A.V., Guedes, R.O.C. and Scofano Neto, F., 2007a, "Bioheat transfer analysis through integral transform techniques" (in Portuguese), Proceedings of the $1^{\text {st }}$ National Meeting in Biomedical Engineering, Petrópolis, RJ, Brazil.

Presgrave, A.V., Guedes, R.O.C. and Scofano Neto, F., 2007b, "Evaluation of the transient temperature field in ischemic brains" (in Portuguese), Proceedings of the $1^{\text {st }}$ National Meeting in Biomedical Engineering, Petrópolis, RJ, Brazil.

Reinders, D.M., Baldwin, S.A. and Bert, J.L., 2003, "Endometrial thermal balloon ablation using a high temperature, pulsed system: a mathematical model", Journal of Biomechanical Engineering, Vol. 125, pp. 841-851. 
Singh, K.C., Sengupta, R., Agrawal, N. and Misra, K., 2000, "Thermal endometrial ablation: a simple technique", Acta Obstetricia Gynecologica Scandinavica, Vol. 70, pp. 54-59.
Villos, G.A., Villos, E.C. and Pendley, L., 1996, "Endometrial ablation with a thermal balloon for the treatment of menorrhagia", The Journal of the American Association of Gynecologic Laparoscopists, Vol. 3, pp. 383-387. 